\title{
Márta Grabócz, Entre naturalisme sonore et synthèse en temps réel Images et formes expressives dans la musique contemporaine
}

(Paris: Éditions des archives contemporaines, 2013

ISBN: 9782813001221)

In view of the history of Western music after World War II, Hans Koessler's notorious statement that the mother tongue of music was German, besides which French could only be a dialect, would seem untenable even from a Hungarian viewpoint. Nevertheless, with respect to Hungarian musicology, this notion appears not to have disappeared. Due to a number of cultural and historical reasons, which I cannot evaluate here, in Hungary the language of musicology - aside from our own and the internationally used English - is still more German than French. In an ideal world we should learn about the methods and achievements of works published in French less sporadically - a fact of course enhanced by Francophone musicology's turning into a kind of enclave inside an ever more Anglicized discipline.

Needless to say, this somewhat peripheral position does not imply an essential lack of interest, let alone complete segregation, since works written in French do appear from time to time on the intellectual horizon of Hungarian musicologists. Unsurprisingly, one of the French-speaking authors who often succeeds in attracting the attention of her Hungarian colleagues is Márta Grabócz, a Hungarian professor teaching at the University of Strasbourg, whose book allows a glimpse into the analysis of contemporary music through up-to-date methods. The title of the volume reads Entre naturalisme sonore et synthèse en temps réel - Images et formes expressives dans la musique contemporaine ('Between sonorous naturalism and real-time synthesis - Expressive images and forms in contemporary music').

Grabócz begins by declaring that, since the appearance of musique concrète and electroacoustic music, the spectrum of potentially 'musical' materials have significantly expanded - partly due to the advances in technology, partly as a 
consequence of the changes in attitudes (p. 3). The main question that the book exposes is whether and how the use of these new materials influenced the concept of musical form. In contemporary music, Grabócz identifies four different styles or tendencies through which this question can be examined: sonorous naturalism (e.g. in the works of François-Bernard Mâche); spectral music (certain works by Kaija Saariaho, Magnus Lindberg, Péter Eötvös, László Dubrovay and Tristan Murail); 'mixed music' (musique mixte), which is based on the interaction of instruments and computers at the actual time of performance (e.g. certain pieces by Philippe Manoury); and postserial, expressive music as it appears in Kurtág's early works, for instance. Grabócz states already in her preface that in the works that make use of new kinds of musical material one frequently encounters the 'recycling' of traditional musical forms (e.g. ABA, other palindromic forms, rondo and other cyclic forms as well as teleological and evolutive models) which - as she hypothetically suggests - aim at creating a bridge between 'old' and 'new' music (p. 3). At the same time, these works also frequently exhibit new types of formal/structural concepts, which are the main focus of the book. These can be divided in the following groups: application of natural models, application of scientific models, application of models borrowed from theories of myth or narrative, stasis-structures - following the sound's 'own organization' -, and graphic macro-structural models - following the structure of a pre-existing drawing or painting (pp. 3-4).

The book is in effect a collection of studies on the main question posed in the preface. While most of them had been published individually earlier, they nevertheless connect with each other so seamlessly that the coherence of the volume proves in no way inferior to that of a 'traditional' monograph. Of the four major parts the first explores the renewal of basic structures and processes in electroacoustic music. In Grabócz's view, even if one encounters traditional juxtaposing, palindromic or (in the sense of program music) descriptive forms here as well, in most cases composers base the structure of their musical processes on radically new kinds of models (p. 13). These might be extra-musical, e.g. natural models - the book includes analyses of a work each by Magnus Lindberg and François-Bernard Mâche, in which the sounds of nature as recorded on tape come to interact with the music played by the instruments at the actual time of performance. These sounding 'raw materials' of different kinds in a sense represent the spheres of nature and culture for both composers, but they approach the problem in opposing ways. With Lindberg the sounds recorded in nature and the music written for the instruments are contrasted as the representatives of nature and culture, the static and the dynamic spheres. Mâche's 'sonorous naturalism' (naturalisme sonore) aims precisely at deconstructing the border between nature and culture; in the piece entitled Maraé, for instance, through the representation of the quasi-initiating 'voyage' as a musical process (p. 15). Naturally, the extra-musical models used for the structuring of musical processes can be derived either from culture or nature, just as the sounds used in the works. According to 
Grabócz, the second category is that of scientific models, and she exemplifies this by analysing a piece based on narratological theories, Costin Miereanu's Labyrinthes d'Adrien, wherein the composer refers to theoretical works exploring the labyrinth-like structure of the modern novel as well as the catastrophe theory that seeks to describe discontinuous processes through coherent mathematical models (p. 17). In order to illustrate her third group of extra-musical models Grabócz presents musical forms based on structural myth analysis, in which the process of musical composition follows heroic narratives both structurally and dramatically (p. 20). According to Mâche, the hero or the musical material must (by analogy of Greek myths) be exposed to danger; enemies try to deviate it, but in the decisive battle they fail to do so thanks to the intervention of magical elements and divine helpers: the hero reaches his goal, the good get their reward, the evil are punished. ${ }^{1}$ The piece entitled Aliunde practically exhibits this very structure: in the six-part musical form, the process which essentially consists of three parts runs its course twice in varied form (p. 21).

However, the radically new types of structures of electroacoustic music go beyond the inclusion of extra-musical models. Grabócz differentiates between two further categories, the first of which she calls structures of stasis. This partly appears as an aesthetic category in the 1980s (in the writings of Jonathan Kramer, Lewis Rowell or Daniel Charles), but also implies a thriving musical practice: musics based on diverse ostinato effects, the 'dense textures' of Ligeti or Xenakis, or certain pieces by Stockhausen based on aleatorical techniques belong here (p. 21). From the late 1970s on a number of works came to light that could plausibly be interpreted a 'stasis music' dealing with the analysis and continuous metamorphosis of sound. Examples include Tristan Murail's Désintegrations, several pieces by Hugues Dufourt (Antiphysis, Saturne), and a number of works by composers active in the Rome studio of Centro di Ricerche Musicali: Laura Bianchini, Michelangelo Lupone, and Luigi Ceccarelli (p. 22). In Grabócz's view a third group consists of works the musical architecture of which follows some kind of graphic or diagrammatic structure. She includes in this category graphic scores from the 1970s (and in some earlier compositions by Stockhausen), in the case of mixte compositions (which 'mix' recorded material and music played in real time) the works that visualize the recorded sounds as well as works the macrostructure of which is based on a pre-existing graphic scheme (pp. 23-30).

Needless to say, electroacoustic music does not exclusively exhibit new musical forms; as Grabócz makes clear at the very beginning, in these compositions one observes a number of traditional principles of form. It is therefore little wonder that an entire chapter is devoted to the structures intermédiaires, which are based on the real-time cooperation of the tape or a computer, while the organization of

1. Ibid. Cf. François-Bernard Mâche, Musique, mythe, nature. Ou les dauphins d'Arion (Paris: Méridiens Klinksieck, $\left.{ }^{2} 1991\right), 15$. 
the new type of material is also influenced by 'traditional' principles of construction (p. 31). Grabócz investigates the impact of variation forms (Tamás Ungváry, László Dubrovay, Trevor Wishart, Philippe Manoury), teleological forms (Péter Eötvös, Michaël Lévinas, Kaija Saariaho) and symmetrical-palindromic forms (Jean-Claude Risset, Philippe Manoury, François Bayle, François-Bernard Mâche) on certain contemporary compositions, and in an additional brief chapter she discusses pieces using wholly traditional forms, e.g. enumerative forms and descriptive or program music (pp. 31-37).

The next chapter deals with the theoretical writings of contemporary composers and introduces the reader to the views of six composers (Mâche, Wishart, Smalley, Miereanu, Sciarrino, Bayle) on musical form and, most importantly, the theories borrowed from semiotics and other disciplines on which these ideas were based. At the end of the chapter we are offered a synthesis concerning those fundamental categories that play a role in the theories of each composer. In essence they all talk about a tripartite temporal structure (beginning or birth, middle or conflict, end), have a predilection for references related to the image of water (gurgling, riffle, undulation, flow, etc.); even if through different notions, they all define some sort of culmination point or climax in the musical process, and the idea of stasis, the lack of motion, is also omnipresent (p. 52).

The concluding chapter of the first major part discusses the narrative forms found in electroacoustic music. In Grabócz's view a renaissance of narrative forms unfolded in the 1980s; a kind of anti-narrative period, in which musics of stasis, oblivion, unmotivatedness came into prominence, whereas temporal experience was put into the shade, sometime as good as disappeared (p. 57). In the very same period electroacoustic music saw the rise of new kinds of narrative forms. Since Grabócz is an internationally known and acclaimed expert on musical narrativity, it is little wonder that she devotes special attention to this topic. ${ }^{2}$ Of the researchers of literary narrativity she once again predominantly cites Greimas and Paul Ricœur, while of the musicologists Eero Tarasti, when she suggests a typology of narrative forms in electroacoustic music after 1980: traditional, deviant/disintegrating, based on extra-musical models, upsetting the hierarchy of narrative categories (pp. 59-62). In conclusion Grabócz evaluates the return of such narrative types as a positive development for the contemporary audience, since it implies the return of 'history' (histoire) and 'reason' (raison) into music (p. 62).

The second major part investigates the role of timbre in the expressive forms of contemporary music. Here the goal is less to elaborate on typology, but rather to provide detailed analyses of works by Manoury and Saariaho (Jupiter and Lichtbogen, respectively) and two compositions by Lindberg (Ur and Joy). In the 
first chapter devoted to Manoury's piece entitled Jupiter, Grabócz formulates the hypothesis that the real-time interaction of computer and instrument (here a flute) seeks to 'reinstate' dramatic construction, narrative macro-form, exploiting the opportunities for cathartic collision in the new world of interactive sounds (p. 65). Manoury reaches his goal through a new kind of hierarchy among the morphological units of music and an archetypal, cathartic dramaturgy in three parts, renewing the symbolic language of musical communication (pp. 94-103). In relation to the works by Saariaho and Lindberg it is once again the graphic concept of macrostructure, articulation according to timbres and issues of psycho-acoustics that come to the fore (pp. 107-124).

The third major part is devoted in its entirety to the aesthetics and poetics of a single composer, François-Bernard Mâche, whose oeuvre Grabócz had discussed in several earlier studies as well. This is the longest among the four parts and strives to demonstrate the composer's theories and their practical realization in ample detail. This endeavour is all the more impressive, since Mâche, a 'demiurge of tones and poeta doctus', is engaged not only in composition and zoomusicology but also several other fields (linguistics, psychology, etc.), therefore his music, which he primarily views as a means to rediscover the sacral/magical sphere, can properly be understood and interpreted only in a wider philosophical/psychologi$\mathrm{cal} /$ cultural anthropological framework (p. 127). In the course of this introduction to the composer's ideas a great variety of issues are touched upon from the problem of European civilization through the history of modern music and zoomusicology to the relationship between music and emotion, or music and language, respectively (pp. 127-138). Nevertheless, Mâche's music is never overshadowed; one receives a detailed overview of his works written in the 1959-1990 period, as categorized according to diverse viewpoints (pp. 139-181). The following chapters no longer survey Mâche's theories and compositional oeuvre in general, but focus on concrete theoretical and practical problems. Topics at stake include the notion of musical archetype in theory and compositional practice (pp. 183-204) and the reliance on natural models in works that use diverse kinds of recorded material and instruments in parallel, as found in different periods of Mâche's compositional oeuvre (pp. 205-220).

For the Hungarian reader, nevertheless, the most intriguing may be the fourth and last part devoted to the music of contemporary Hungarian composers, in particular György Kurtág and László Dubrovay. In a sense Grabócz fulfils a mission by including studies of Hungarian composers in each of her books, ${ }^{3}$ but for the Hungarian reader her work seems of prime interest since it provides information about how an analyst who has dealt for several decades with contemporary West-

3. Besides, Grabócz also seeks tirelessly to make scholars in the West familiar with the achievements of the 'classics' of Hungarian musicology (József Ujfalussy, Bence Szabolcsi). 
ern music and has accordingly developed a somewhat 'international' perspective, views the works of the composers so familiar to us. The chapter devoted to Kurtág searches for archetypical stylistic features in the composer's works from op. 1 to 7, but Grabócz concludes that it is in fact one of the essential characteristics of Kurtág's works that they resist analysis due to their complexity, their strong stylization of forms and types of utterances inherited from the past, as well as their high-level intertextuality (pp. 224-225). The study nonetheless seeks to enumerate the elements of articulation observed in Kurtág's works and identify their role in each composition: besides op. 1-7 also in Four Songs to Poems by János Pilinszky, op. 11, and Games (p. 226). The rest of the study presents a detailed typology for the works in question, dividing the diverse movements in three main groups as defined by the factor determining their musical articulation: compositional technique, a traditional form known from the history of music, or a specific descriptive or expressive content, respectively (pp. 227-247). The three main categories are further divided into a number of subtypes, and Grabócz also presents a brief case study about one of the movements in Kurtág's Szálkák [Splinters] op. $6 \mathrm{c}$, describing the musical process from bar to bar according to her specific viewpoints: 'direction', question-answer articulation, set of notes, pitch set, intervals, character, dramaturgy and teleology (pp. 247-250). There is arguably no better way than Grabócz's analysis to plastically demonstrate through the means of musicology the extreme density and (notwithstanding the short duration) the outstanding complexity of Kurtág's music, which average listeners also experience.

The last chapter investigates the relationship between innovation and tradition in the works of László Dubrovay. Grabócz's discussion proves of great interest since she approaches these works from the same perspective as the works by Mâche, Murail and Saariaho, among others. Here as well, her discussion of Dubrovay's 1980s works (Quartet No. III, Solos Nos. 3 and 5, Octet, Symphonia) focuses on the synthesis of new types of sounds (the parallel use of harmonic tones, microchromatic relations and noises) and $18^{\text {th }}$ - and $19^{\text {th }}$-century styles and forms. For Grabócz the composer's 'synthesizing experiment' aims at recreating the 'traditional dramaturgy' with new types of sounds (p. 256). She argues for the validity of sonata and rondo forms, character variations and other familiar formal designs in works that aim at reconciling the traditional with the new.

Overall, the volume provides a multifaceted and reflective overview of the relationship between new and old, innovation and tradition in contemporary music. It conveys a coherent image based on the vast experiences of a researcher who is thoroughly familiar with innovative musical structures and has the appropriate analytical approaches at her command. Márta Grabócz's book proves to be an encyclopedical summary of several decades of pioneering scholarly activity.

Dániel NAGY 